\title{
Research on PE Tutoring Service Strategy under the Background of New Curriculum Standard
}

\author{
Ying Tang, Xin Weng*, Leijie Gong \\ Zhejiang Normal University, School of College of Physical Education and Health Sciences, Jinhua, China \\ Email: *860868316@qq.com
}

How to cite this paper: Tang, Y., Weng, X. and Gong, L.J. (2021) Research on PE Tutoring Service Strategy under the Background of New Curriculum Standard. Open Access Library Journal, 8: e7366.

https://doi.org/10.4236/oalib.1107366

Received: March 29, 2021

Accepted: April 23, 2021

Published: April 26, 2021

Copyright $\odot 2021$ by author(s) and Open Access Library Inc.

This work is licensed under the Creative Commons Attribution International License (CC BY 4.0).

http://creativecommons.org/licenses/by/4.0/

\section{(c) (i) Open Access}

\begin{abstract}
With the development of social economy, the implementation of the national fitness plan and people's attention to their health, physical education has become a unique way of life. Tutoring institutions are educational institutions that provide "one-to-one" individual academic guidance for learners in their families or tutoring institutions. The emergence and development of tutoring institutions has its historical inevitability, which is closely related to the enhancement of social competition consciousness, the disadvantage of large class teaching, the lack of social and economic status of teachers and the educational concept of parents. The target range of physical education has been broadened. For children please sports tutoring is a very common social phenomenon, but this does not mean that only children need to please family tutoring, in a narrow sense, the main object of sports tutoring is for children (primary and middle school students) groups. With the continuous development of the society and the different needs of the members of the society, the target range of physical education has been expanded. In a broad sense, all the people who have sports training needs can ask for sports tutoring, therefore, sports tutoring is a kind of personalized sports education services in essence. At present, although the physical education institutions have obtained unprecedented development, but through the investigation found that physical education also has some problems, such as through non-standard publicity, random fees, tutoring quality is difficult to guarantee. The existence of these problems is not correct, driven by interests, internal management strategy is not in place, the idea of running a school of sports tutoring institutions is too profit-oriented. To solve these problems, PE tutors should pay attention to the content and ensure the quality; Reasonable publicity, create brand; Stabilizing teachers, strengthening training, expanding scale, strengthening marketing and so on. At present, whether the development needs of students can
\end{abstract}


be taken as the ultimate starting point is an important factor affecting the survival and development of tutoring institutions. This paper adopts a variety of research methods such as literature method, interview method, questionnaire survey method and mathematical statistics method. All of these situations are the actual problems that all of us sports workers must face. Facing these problems, we must effectively solve the problems, in order to provide theoretical basis for the research of sports tutoring service strategy under the background of the new curriculum standard.

\section{Subject Areas}

Physical Education

\section{Keywords}

Physical Education Service, Physical Education Institutions, Influencing Factors

\section{Introduction}

The physical health level of young children determines their physical and mental development level [1]. To improve the physical health level of young children by sports is mainly manifested in the improvement of physical quality, the enhancement of physical function and the perfection of body shape and development. The physical health of young children is the foundation of the health quality of our whole nation. Sports can promote the physical development and physical enhancement of young children. In today's living and social environment, strengthening physical education is a necessary condition to improve the physical health level of young children. The logical implication is that if physical education is not strengthened, the physical health level of young children cannot be improved. However, under the condition of objective bias, ineffective means and one-sided approaches, strengthening physical education may not be able to improve their physical health level. Because a strong physique is not a natural result of physiological development, nor is there no goal, means, methods, rules, only sports competitive entertainment can be achieved, it is achieved by scientific physical exercise and health care. Reasonable goals and approaches, effective methods and means, as well as active physical exercise and health care, can promote metabolism, enhance organ function and improve physical fitness. therefore, we must correctly understand the concept of "green children's sports", on the basis of a clear blue children sports what "strengthening", "who to strengthen", where is the "strengthening", such as basic issues, to explore to adapt to the characteristics of green children's sports teaching and activity form, to guide the green children's purposeful, planned and regular physical exercise, effectively improve the students' body form and function, improve exercise capacity, efforts to achieve good physical health standard. Put the youth sports into 
practice, and then let strengthen the youth sports to improve their physical health level of the necessary and sufficient conditions.

The new PE curriculum standard points out that PE teachers should "play". Fully understand the students, seize the characteristics of students' subjectivity play, under the correct guidance of teachers, actively participate in learning and their own development shows a subjective initiative. Stroke; finally, students should be taught to consciously and effectively regulate the process of learning and fitness, and objectively check and evaluate the effects of learning and exercise.

With the parents of the children's physical quality of the increasing attention, the entrance examination total score, more and more parents will give their children to hire a sports tutor, and many cram schools are aiming at this market demand to open a sports cram school. "Sports tutoring" is mainly to accompany students to do sports and teach some sports skills, or for a specific sports test in the middle school entrance examination.

Compared with ordinary tutoring, the fee of "sports tutoring" is higher, about 100 yuan per hour, most of it is 1-to-1, once or twice a week, each time lasts 1 to 2 hours. To tell students some theoretical knowledge that is beneficial to physical health. Academic tutors are afraid of naughty children, but PE tutors are on the contrary, they like active students most, they usually can quickly master the gist of a certain skill. But every student's physique and personality are different.

I think the rise of PE tutoring is a good phenomenon, which shows that parents have gradually come out of the "heavy intelligence, light body" misunderstanding. The rise of PE tutoring reflects parents' attention to children's physical quality. Nowadays, primary and middle school students have a heavy study burden, children have less and less time to exercise, and health problems such as obesity and myopia are becoming more and more serious. The heavy academic burden makes the children "afraid to play", and the parents' high expectations make the children "have no time to play". As a result, the children become "stay-at-home children" who "can't play". Now the children of the definition of "play" is to chat on the Internet, play games, if the holiday or weekend to ask a sports tutor to help children exercise, can not only strengthen the body, but also to avoid children addicted to the Internet, the best of both sides.

\section{Research Objects and Research Methods}

\subsection{Research Object}

The research object is physical education tutoring for junior and senior high school students in Yongzhou.

\subsection{Research Object}

\subsubsection{Literature Method}

Through a large number of access to China Journal Network, Hunan Institute of Science and Technology Library and other relevant literature, and carefully read, 
summarize, with relevant materials, literature for the research and analysis of this topic to provide the necessary theoretical basis.

\subsubsection{Questionnaire Survey}

Starting from the purpose of the study, the object of this study is to conduct a comprehensive investigation and analysis on the influencing factors of $\mathrm{PE}$ tutoring demand among the PE students in Yongzhou No. 1 Middle School, Dongan Chengjiang Middle School in Grade 3 and Grade 3, and obtain data.

Questionnaire design: according to the requirements of the questionnaire design, through literature review, expert visit and other ways, combined with the actual situation of junior and senior high school students who participated in the physical education examination, the questionnaire of "PE Tutoring Service Strategy under the New Curriculum Standard" was designed. After the expert validity and the consensus of the experts, the students in Yongzhou No. 1 Middle School and Dongan Chengjiang Middle School who participated in the physical examination were investigated [2].

Questionnaire survey time: January - February 2020.

In all the questionnaires, only incomplete background information, same handwriting, missing selection and multiple selection were excluded as invalid questionnaires. Questionnaire reliability: to ensure the reliability and validity of the questionnaire, this paper USES the weight measurement method, design the questionnaire first in Yangzhou one and dong Chengjiang middle school makes a issued two questionnaire survey of 80 people for the questionnaire after 15 days, after a full recovery, after the second questionnaire 80 after reliability test, the questionnaire reliability coefficient is 0.85 , conform to the inspection requirements of the reliability of questionnaire design.

Questionnaire validity: A total of 6 copies of questionnaires recycling 6 copies of valid questionnaires 6 copies of effective recovery rate 100\% (Table 1 and Table 2).

\subsubsection{Interview Method}

To take advantage of the opportunity of a questionnaire, Yongzhou and Dong

Table 1. Statistical table of expert information for validity evaluation.

\begin{tabular}{ccc}
\hline Professor & Associate professor & Total \\
\hline 2 & 4 & 6 \\
\hline
\end{tabular}

Table 2. Statistical table of validity evaluation results.

\begin{tabular}{ccc}
\hline Validity & Frequency & Percentage \\
\hline Totally agree & 3 & $50 \%$ \\
Relatively match & 3 & $50 \%$ \\
Conform & 0 & $0 \%$ \\
Not conform & 0 & $0 \%$ \\
\hline
\end{tabular}


Chengjiang middle school's high three students talked at the beginning, through the conversation understanding about tutoring service situation of physical education and influence in the early three influence factors of tutoring students participate in sports training, and at the same time and will face body exam at the beginning of the third year students talking face to face, in order to understand early three part of the body on student demand for sports tutor personal views and suggestions.

\section{Analysis of Research Results}

\subsection{Basic Information of Physical Education}

Through Table 3 project survey of sports tutor, you can see is mainly reflect the concentration and trends of the project, prompting the swimming events in which sports tutor form a huge market, the largest sports tutor and motivation of "physical examination (tests)", aimed at to swim through swimming test the measures to improve the penetration rate, reduce the swimming events of the drowning of primary and middle school students, improve the physical health of primary and middle school students, alleviate the pressure of the school, as a result, students focus on examination of the previous year and summer vacation in the swimming pool sports family education and training; Secondly, basketball, badminton and table tennis accounted for $19.0 \%, 3.2 \%$ and $4.4 \%$ respectively. This is because table tennis is a national sport and basketball and badminton have a high popularity rate, good foundation and easy development among the whole people. Then track and field, football, martial arts, tennis and sports dance accounted for $8.2 \%, 7.9 \%, 3.7 \%, 2.6 \%$ and $0.8 \%$ respectively, because most of the students took improving their physical fitness, enriching their cultural life outside school and cultivating their sentiment as their main motivation.

Table 3. List of market training programs and contents.

\begin{tabular}{ccc}
\hline Sporting events & The number & Percentage \\
\hline Swimming & 165 & 29.1 \\
Basketball & 108 & 19.0 \\
Athletics & 47 & 8.2 \\
Martial arts & 21 & 3.7 \\
Sports dance & 5 & 0.8 \\
Gate ball & 20 & 11.9 \\
Snooker & 15 & 8.1 \\
Table tennis & 8 & 4.4 \\
Badminton & 6 & 3.2 \\
Gas volleyball & 9 & 4.9 \\
\hline
\end{tabular}




\subsection{Current Situation of PE Tutoring Service under the Background of New Curriculum Standard}

\subsubsection{Time Requirement of PE Tutor}

According to the survey (Table 4) results show that the primary and middle school students in choosing sport tutor basic synchronization time, because a lot of students in sports tutor at the same time, parents also for their intensive course owners hired outside of school tutoring lessons and other training courses, therefore, choose sports family education has the highest number of double cease day, accounted for $43.2 \%$; The number of people who participated in PE tutoring training in extracurricular time and winter and summer holidays followed, accounting for $24.5 \%$ and $23.8 \%$ respectively. Sports tutoring in the evening were also a minority (8.4\%). From the overall situation of the sports tutoring training market in Ningbo.

\subsubsection{Sports Tutoring Places Demand}

To some extent, the guarantee of PE tutoring behavior on teaching quality reflects the good and bad of PE tutoring places. The survey (Table 5) shows that the sports tutoring venues basically meet the teaching requirements. Due to the restrictions of sports tutoring projects and safety factors, the school venues, venues and for-profit places (natatorium) become the preferred places to participate in sports tutoring training, accounting for $37.5 \%$ and $35.6 \%$ respectively; Followed by rental space, accounting for $10.9 \%$ of the total; Parks, community sports and natural venues accounted for 6.3 percent, 5.4 percent and 4.0 percent, respectively.

\subsubsection{Sports Tutoring Exercise Project Needs}

According to the data in Table 6, among the junior and senior three students surveyed, there are different sports tutoring programs. 23 students choose 100 -meter sprint as the sports tutoring training program. 16 people chose swimming sports tutoring training program, accounting for $8.6 \%$ of the total number; there are 8 students, 8 students, 6 students and 9 students in sports tutoring training programs of sports dance, table tennis [3], badminton and air

Table 4. The time period of PE tutoring.

\begin{tabular}{ccccc}
\hline Time to choose & Double cease day & Outside of class time & Holiday & Evening \\
\hline Number & 245 & 139 & 135 & 48 \\
$\%$ & 43.2 & 24.5 & 23.8 & 8.4 \\
\hline
\end{tabular}

Table 5. List of places to participate in sports tutoring.

\begin{tabular}{ccccccc}
\hline $\begin{array}{c}\text { Site } \\
\text { type }\end{array}$ & $\begin{array}{c}\text { School } \\
\text { venues and } \\
\text { venues }\end{array}$ & $\begin{array}{c}\text { Profit place } \\
\text { (Natatorium) }\end{array}$ & $\begin{array}{c}\text { Tenancy } \\
\text { space }\end{array}$ & Park & $\begin{array}{c}\text { Community } \\
\text { sports venues }\end{array}$ & $\begin{array}{c}\text { Natural } \\
\text { sites }\end{array}$ \\
\hline Number & 213 & 202 & 62 & 36 & 31 & 23 \\
$\%$ & 37.5 & 35.6 & 10.9 & 6.3 & 5.4 & 4.0 \\
\hline
\end{tabular}


Table 6. Statistics of the demands of PE tutoring programs for junior high school students.

\begin{tabular}{ccc}
\hline Physical Education Tutoring Program & Number & Percentage \\
\hline 100-meter sprint & 23 & 12.4 \\
Swimming & 16 & 8.6 \\
Sports dance & 8 & 4.3 \\
Martial arts & 21 & 3.7 \\
Snooker & 15 & 8.1 \\
Table tennis & 8 & 4.4 \\
Badminton & 6 & 3.2 \\
Gas volleyball & 9 & 4.9 \\
\hline
\end{tabular}

volleyball, respectively, examination policy has fully activated the whole P.E. tutor market in Yongzhou City, and it shows the very strong motivation of utilitarian participation.

\subsubsection{The Current Situation of the Demand of Junior High School Students' Attitude towards PE Tutoring}

According to Table 7, 131 students, accounting for $70.8 \%$ of the total, know about physical exercise in junior and senior three. Among them, 32 people were very familiar with them, accounting for $17.3 \%$ of the total, and 17 people were very familiar with them, accounting for $9.2 \%$. The number of people who know and do not know are 3 and 2 respectively, accounting for $1.6 \%$ and $1.1 \%$ of the total number of people. This shows to strengthen the youth sports, enhance the youth physique. It is imperative that school physical education teachers, in particular, should fully understand the "sports tutor" to strengthen the necessity and importance of children's sports, the propaganda, guide for students and parents [4], so that they recognize "sports tutor" targeted to strengthen physique and promoting the importance of comprehensive development as an important content of school sports work, and help parents to solve in the "sports tutor" encountered in the implementation of such as physical fitness, sports knowledge technology, main point, principle, teaching methods and infiltration in sports psychology, moral, intellectual, aesthetic education, and other issues. At the same time, for those families who do not have physical education conditions, physical education teachers can help recommend physical education tutors. Of course, physical education teachers in students' schools are supposed to participate in paid physical education tutoring in their spare time.

\subsubsection{Physical Education Consumption Level}

The statistical data in Table 8 show that the fees of high school entrance examination subjects are relatively popular, the price is $20-30$ yuan/hour, the number of students is moderate, and the teaching is mainly in small classes. The teaching of swimming is given priority to, the total teaching time of each period is $10-15$ 
Table 7. The degree of understanding needs of junior high school students on PE tutoring.

\begin{tabular}{ccc}
\hline Validity & Frequency & Percentage \\
\hline Know very well & 17 & 9.2 \\
Know a lot about & 32 & 17.3 \\
To understand & 131 & 70.8 \\
General understanding & 3 & 1.6 \\
Don't understand & 2 & 1.1 \\
\hline
\end{tabular}

Table 8. Charge basic information of different types of items.

\begin{tabular}{llll}
\hline \multicolumn{1}{c}{ Project } & \multicolumn{1}{c}{ Rates } & $\begin{array}{c}\text { Number of } \\
\text { students }\end{array}$ & \multicolumn{1}{c}{ Site } \\
\hline An examination of the project & $\begin{array}{l}20-30 \\
\text { Yuan/Hour }\end{array}$ & $10-15$ people & Free \\
Swimming & $30-40$ Yuan/time & $10-20$ people & Free \\
$\begin{array}{l}\text { Ball games (badminton, table } \\
\text { tennis, tennis) }\end{array}$ & $\begin{array}{l}40-80 \\
\text { Yuan/Hour }\end{array}$ & $4-8$ people & $\begin{array}{l}\text { Bring your own } \\
\text { racket, the rest is free }\end{array}$ \\
Martial arts, art & $30-40$ Yuan/time & $6-10$ people & Free \\
\hline
\end{tabular}

lessons, the total cost is $400-600$ yuan, which is also the form of small class teaching. In order to ensure the quality of teaching, the number of students should not be too large, so the charge is between 40 and 80 yuan per hour. Martial arts, arts and sports are also implemented in small class teaching, the cost is not high, 30 - 40 yuan/time. Since 2009, Yongzhou junior high school students in the graduation entrance examination of the weight of the physical education test will be increased, such a policy change, constantly promote the development of the sports tutoring market.

\section{Analysis of PE Tutoring Strategy under the Background of New Curriculum Standard}

\subsection{National Policies and Macro-Control on Physical Education}

Recently, the Ministry of Education has issued "opinions on strengthening the work of PE tutoring" [5], making overall use of social resources, and supporting parents' schools, have been arranged and arranged in detail, which provides practical and operable guidance for the development and promotion of PE tutoring work throughout the country. The importance of PE tutoring is self-evident, $\mathrm{PE}$ tutoring is a key to unlock a lock, the essence is to let students learn to respect life, so PE tutoring is very important, only fully pay attention to PE tutoring, home and school reasonable, in order to make the flowers of the motherland more robust growth.

The symposium, the participants reached a consensus, will comprehensively promote the work of physical education [3]. At present, the National Institute of 
Administrative Education, Sports Tutoring Training Center and China Sports Management Association jointly set up a leading group, jointly promote the popularization of sports tutoring, to achieve home-school co-education, home-school co-construction, and to comprehensively promote the implementation of the overall work of physical quality education for teenagers is an urgent matter. The macro-control of national sports tutoring is reflected in that the Chinese Sports Management Association and the only designated training and group standard of "China Sports Tutor Instructor" jointly participate in the joint certification unit shows that: We will unswervingly to let Chinese families healthier this great mission, attaches great importance to the family health civilization construction, make more family master scientific and proper physical exercise way, promote the development of sports school, is that we always stick to the responsibility, taking the beginner's mind, self-motivated, we've been on the road.

\subsection{Social Market Demand for PE Tutoring}

Physical education in the family education market share, there is an expanding trend. Under the guidance of sports policy in the middle school entrance examination, the pattern of sports tutoring has added a new main force. For the sake of children's future and the national physique, experts and scholars even proposed to include sports items in the college entrance examination. All this indicates that the phenomenon of PE tutoring will be heating up in the future. Therefore, the key to treat $\mathrm{PE}$ tutoring rationally lies in correct guidance and strengthening management, and the way out is to regulate PE tutoring market. Since 2009, the Beijing municipal junior middle school students in the graduate entrance examination physical exam weight will increase, this change in policy, constantly promote the development of sports tutor market, however, as people material life level of ascension, our country still need to improve the physical health of youngsters' and children's level, so that more and more parents begin to pay attention to the child's physical health, is also the reason that promoted sports tutor continue, market demand for sports family education continues to rise.

\subsection{The School Has Strict Requirements for Physical Education Examination}

In April each year, the sports entrance examination starts all over the country one after another. In the forums related to the sports entrance examination, the "third party of junior high school" attempts to "cram at the last minute" the most posts, and in the comments, in addition to expressing sympathy replies, there are also advertising links of major training institutions. Now is really the peak season in the industry, but our course arrangement and enrollment will not be enlarged, to one to one. In the off-season, the shift is more abundant. Beijing a sports examination training institutions coach Tang Chao admitted that the closer to the physical examination, parents and children on the greater the demand for sports tutoring at this time, often will lead to the development of the 
market of sports tutoring, due to the advent of sports examination, promote the rise of sports tutoring.

\subsection{Family and Personal Requirements for Physical Health}

"Physical education" with family education as the theme is necessary and important for families and individuals. However, teenagers need the "care" of family physical education, especially the "synchronous tutoring" of family physical education when they receive school physical education. Strengthen the youth sports, strengthen the younster health is one of the important meaning, sports tutor rise is the bounden duty of sports tutoring industry and responsibility, the youth physical and mental health, fitness, strong-willed, full of vitality, is the embodiment of the exuberant vitality of a nation, is a sign of social civilization, is one of the most important aspects of the national comprehensive strength. The happiness index of the family needs to take the physical health as the foundation, the personal growth also needs to take the physical health as the foundation, so the physical health is the foundation of everything we pursue. This has given birth to the rise and development of sports tutoring, sports tutoring into the family to go, is an inexhaustible wealth.

\section{Conclusions and Suggestions}

\subsection{Conclusion}

The motivation to hire a sports tutor has changed a bit. Scores are no longer the only reason they hire a sports tutor for their children, but also for their children's health and future. The concept of parents cultivating their children has changed from a single "intellectual education" to an all-around development. It is an inevitable choice for adults to employ sports tutors to integrate sports into a healthy lifestyle. Physical education cannot be short-sighted, cannot one-sided pursuit of immediate results, physical education can be said to be an organic part of the whole life to receive education. Physical activity is an investment in health whose returns will last a lifetime. Diversification of the source channels of teachers Physical education teachers' source is very wide, different sports items, by different nature of the teachers. Although the teachers come from different groups of people, they all have the common characteristics of physical education teaching ability, have rich teaching experience, and are good at certain sports skills. Fees are market-oriented, the degree of social and economic development is relatively low, people's sports consumption awareness and consumption level is not high, sports tutoring fees are mainly regulated according to the supply and demand relationship of the buying and selling market and the living consumption level of local people, the market price is low. The self-regulation of the market will inevitably have opaque factors. It is suggested that education, industry and commerce, and price departments give guiding opinions on the pricing standard of the tutor market, and make public the standard basis for the implementation of fees, so that the consumers of the sports tutor can clearly consume 
[6].

\subsection{Suggestion}

Some sports tutoring institutions believe that, although there are some very good sports tutoring institutions all over the country, occupy the local main market, but on the national scale, is still in the situation of divided groups. Although the "bellwether" has appeared, but there has not been an absolute advantage of the physical education institutions. The competition in the tutor market is fierce, but there is a lack of corresponding supervision and fair industry standards. At present, the government and education committee has no related policy to protect standard operating sports family education institutions, for their own business, the first sports family education institutions to provide good service, you must give need fitness of students with a good teacher, and use a separate space, on the other hand, the number of good sports teacher is very limited, nature is not cost-effective to use these teachers. After paying such a high price, parents have high expectations for the improvement of academic performance. In fact, there are many factors affecting academic performance, which are very complex, which cause great problems for the operation and management of sports tutoring institutions. Therefore, reasonable treatment of fees, as well as establish a good reputation.

Whether children or adults, the time period of physical education tutoring is after their own study or work. The student group is mainly concentrated in the long vacation in winter and summer, while adults are in the weekends and ordinary evenings. It really varies from person to person and the overall teaching period is reasonable. Different types of physical tutors use different teaching facilities, school sites and operating facilities are better, can meet the needs of teaching, public sports facilities and park clearing the fields exist safe hidden trouble, the more interference factors, is not conducive to carry out teaching, is not advocated to teaching in these places.

\section{Conflicts of Interest}

The authors declare no conflicts of interest regarding the publication of this paper.

\section{References}

[1] Liang, H.B. (2010) Analysis of the Reasons for the Phenomenon of Sports Tutoring Popular Market. Journal of Physical Education College of Shanxi Normal University, 25, 66-68.

[2] Lin, Z.F. (2000) University Psychology. Zhejiang University Press, Zhejiang.

[3] Fang, S.J. (2012) Investigation and Thinking on the Present Situation of Physical Education in Zhejiang Province. Journal of Zhejiang Ocean University (Humanities Edition), 96-101.

[4] Wu, X.D. (2012) Family Physical Education is an Important Basis and Way to Strengthen Children and Adolescents' Physical Education. Journal of Sichuan In- 
stitute of Education, 8, 120-124.

[5] Yang, G.R. (2007) Understanding and Strengthening Physical Education from a Strategic Perspective. China Higher Education, 11, 12-13.

[6] Gong, J.Q. and He, Z.W. (2018) Analysis on the Development Status of College Students' Tutoring Industry. New West, 27. 